\title{
Classificação dos tumores da mama: atualização baseada na nova classificação da Organização Mundial da Saúde de 2012
}

Primeira submissão em 23/10/12 Última submissão em 23/10/12 Aceito para publicação em 22/11/12 Publicado em 20/12/12

\section{Classification of tumours of the breast: an update based on the new 2012 World Health Organization Classification}

Helenice Gobbi

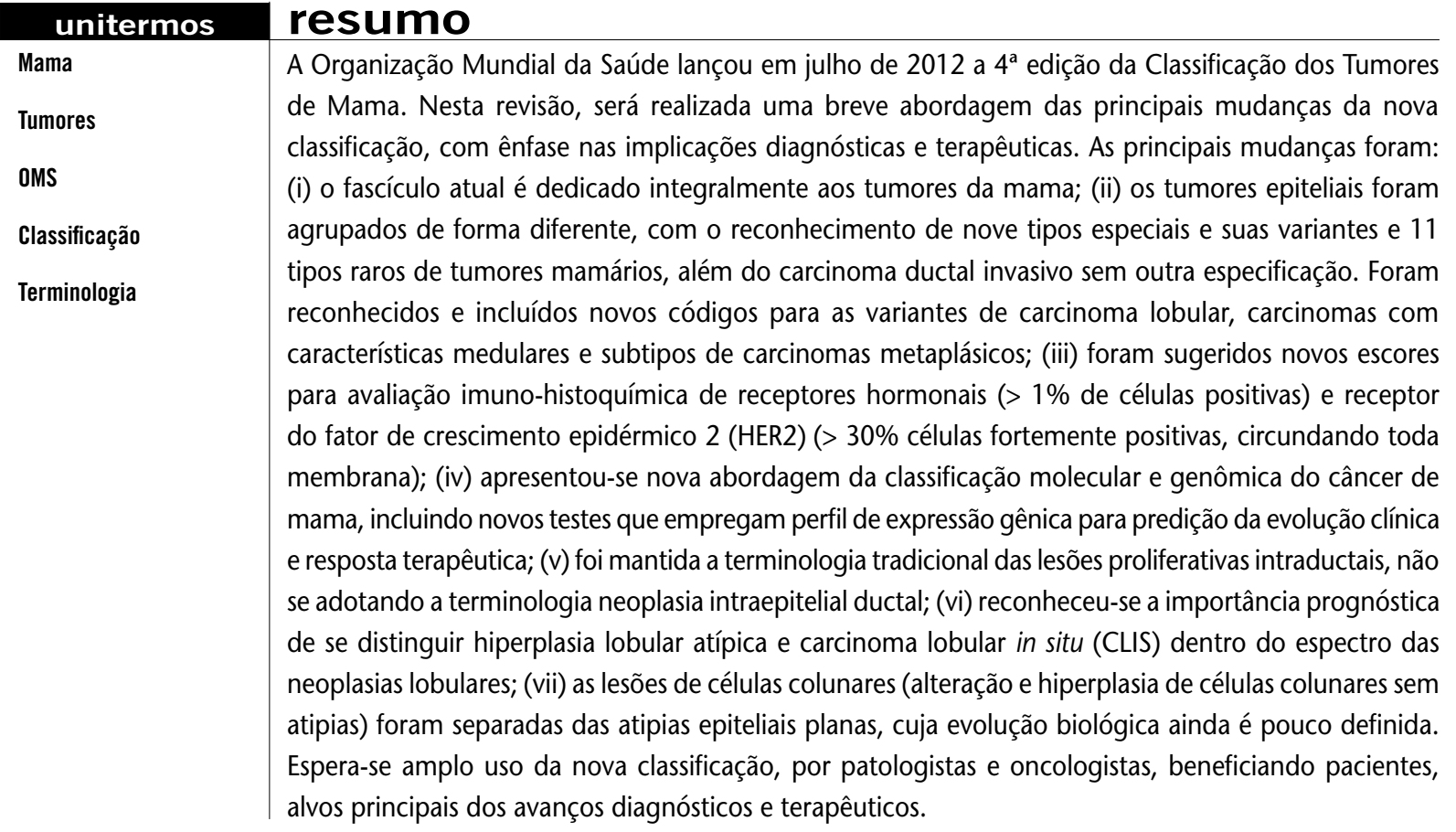

abstract

The World Health Organization released the 4th edition of the Classification of Breast Tumors in July 2012. This review summarizes the principal changes that were introduced in the new classification with emphasis on diagnostic and therapeutic implications. The major changes were: (i) the new edition is entirely dedicated to breast tumors; (ii) the epithelial tumors were sorted differently, recognizing nine special types and variants, and eleven rare types of breast tumors apart from invasive ductal carcinoma of no special type. New codes were included for the lobular, medullary, and metaplastic subtypes; (iii) new scores were suggested for the immunohistochemical evaluation of hormone receptor (> 1\% positive cells) and human epidermal growth factor receptor 2 (HER2) (> 30\% highly positive cells surrounding the whole membrane); (iv) a new approach to molecular and genomic classification of breast cancer was presented including predictive and prognostic tests using gene expression profile; ( $v$ ) the traditional terminology of intraductal proliferative lesions was maintained and the terminology ductal intraepithelial neoplasia was not recommended; (vi) the prognostic importance of distinguishing atypical lobular hyperplasia and lobular carcinoma in situ (LCIS) within the spectrum of lobular neoplasia was acknowledged; (vii) the columnar cell lesions (columnar cell change and columnar cell hyperplasia without atypia) were excluded from the flat epithelial atypia group, whose biological behavior is still unknown. It is expected that the widespread use of the new classification by pathologists and oncologists will benefit patients by improving diagnostic and therapeutic decisions. key words

Breast

Tumors

WHO

Classification

Terminology 


\section{Introdução}

As classificações de tumores tornaram-se parte integrante da oncologia moderna e, para patologistas, elas fornecem guias e recomendações que facilitam a reprodutibilidade diagnóstica e prognóstica. Nas duas últimas décadas, a publicação da Classificação de Tumores da Organização Mundial da Saúde (OMS) para diversos sistemas tornou-se importante referência para patologistas e oncologistas, com ampla aceitação internacional. Os livros são editados pela International Agency for Research on Cancer (IARC) e referidos pelos patologistas como blue books, pois, em sua primeira edição, eles tinham capa azul. Nas primeiras edições dos blue books, um editor de renome internacional e alguns poucos colaboradores eram responsáveis pela edição de cada volume. Nas séries mais recentes, uma abordagem diferente foi adotada, tanto em relação à autoria quanto ao conteúdo. Nos volumes mais recentes, conta-se com dezenas de colaboradores que incluem, além de patologistas, geneticistas, biólogos moleculares, clínicos, cirurgiões e outros, na tentativa de incluir e garantir a participação de numerosos experts, representantes de diversas regiões do mundo. Diferente de ser apenas um catálogo de tumores, como nas primeiras edições, as séries atuais da OMS incluem texto detalhado e numerosas ilustrações, descrevendo características clínicas, epidemiológicas, anatomopatológicas, genéticas e evolutivas de cada entidade. A importância dos livros, cuja edição ocorre a cada oito a 10 anos, é oferecer à comunidade médica e científica internacional uma publicação de referência, concisa, contendo critérios diagnósticos padronizados e aceitos consensualmente. Os livros servem de guia para patologistas, oncologistas e outros pesquisadores para o desenho de estudos clínicos, a monitoração de resposta terapêutica e a evolução clínica de pacientes.

A IARC lançou em julho de 2012 a $4^{a}$ edição do livro "Classificação de Tumores da Mama da Organização Mundial da Saúde", que é o volume 4 , da $4^{\text {a }}$ série da Classificação Histológica e Genética dos Tumores Humanos ${ }^{(27)}$. Essa edição contou com a colaboração de 90 representantes da comunidade científica internacional que escreveram os diferentes capítulos. Além de patologistas com especialização em patologia mamária, essa edição contou com especialistas em patologia de partes moles, hematopatologia, dermatopatologia, além de oncologista clínica, cirurgiã oncológica, radiologista, biólogos moleculares e geneticistas. Após receber todos os capítulos, a OMS convidou os editores e um grupo de autores/experts referidos como Comitê de Consenso ou Working Group para reunião presencial, a qual se realizou em Lyon, na França, de $1^{\circ}$ a 3 de setembro de 2011. Os capítulos enviados pelos diferentes colaboradores foram exaustivamente revistos e discutidos pelos editores e Working Group até se obter o consenso do conteúdo final, que resultou no volume lançado em julho de 2012.

O Comitê de Consenso envolvido na revisão dos capítulos e edição final do fascículo de tumores de mama incluiu 10 patologistas de competência reconhecida, representativos de diferentes regiões do mundo, uma oncologista clínica, uma cirurgiã oncológica, uma geneticista molecular e um especialista em codificação internacional de doenças oncológicas (ICD-O code). Embora as descrições dos tumores e lesões constantes no livro da OMS tenham sido feitas por autores individuais, o Comitê de Consenso reunido em Lyon editou e aprovou todo o texto. Essa nova abordagem da OMS busca assegurar que a classificação atual represente uma visão de consenso ampla, que, aliada a texto mais abrangente, com inclusão de aspectos genéticos e moleculares, continue a garantir que esta seja a Classificação de Tumores de Mama mais popular e moderna a ser usada por patologistas e oncologistas. O uso dessa nova classificação pelos patologistas, empregando critérios bem padronizados e amplamente aceitos, irá colaborar na reprodutibilidade de diagnósticos e poderá permitir melhor avaliação preditiva do potencial biológico das lesões e possível resposta aos tratamentos.

O objetivo desta atualização é destacar as novidades e as mudanças apresentadas nesta $4^{\text {a }}$ edição de 2012, em relação à $3^{a}$ edição publicada em $2003^{(50)}$, com ênfase nas implicações diagnósticas, evolutivas e terapêuticas.

\section{Principais mudanças da $4^{a}$ edição}

Diferentemente da $3^{\mathrm{a}}$ edição( ${ }^{(50)}$ que englobava também os tumores dos órgãos genitais femininos, a $4^{\mathrm{a}}$ edição ${ }^{(27)}$ é dedicada integralmente aos tumores da mama.

\section{Tumores epiteliais}

Os tumores epiteliais foram agrupados de forma diferente (Tabelas 1 e $\mathbf{2}$ ), com o reconhecimento de nove tipos especiais e suas variantes e 11 tipos muito raros de tumores mamários, além do carcinoma ductal invasivo sem outra especificação (CDI-SOE). Entre os subtipos especiais, foram incluídos os carcinomas lobulares invasivos, tubular e cribriforme, carcinomas com características medulares, carcinoma metaplásico, carcinoma com diferenciação apócrina, tumores tipo glândula salivar/anexos cutâneos, 
carcinoma adenoide cístico, carcinoma mucoepidermoide, carcinoma polimorfo, carcinomas mucinosos e com diferenciação em células em anel de sinete, carcinomas com elementos neuroendócrinos, carcinoma papilar invasivo e os tipos excepcionalmente raros e suas variantes. Dois padrões clínicos, carcinoma inflamatório e carcinomas mamários bilaterais sincrônicos e não sincrônicos, também foram incluídos na abordagem dos subtipos especiais.

\section{Tabela 1 Mama da OMS}

\section{Tipos de tumores epiteliais segundo a $3^{\mathrm{a}}$ e $4^{\mathrm{a}}$ edições da Classificação Histológica de Tumores da}

\begin{tabular}{|c|c|}
\hline $3^{\text {a }}$ edição (2003) & $4^{\mathrm{a}}$ edição (2012) \\
\hline & Carcinoma microinvasivo \\
\hline $\begin{array}{l}\text { Carcinoma ductal invasivo, SOE } \\
\text { Carcinoma tipo misto } \\
\text { Carcinoma pleomórfico } \\
\text { Carcinoma com células gigantes tipo osteoclasto } \\
\text { Carcinoma com elementos coriocarcinomatosos } \\
\text { Carcinoma com elementos melanóticos }\end{array}$ & $\begin{array}{l}\text { Carcinoma mamário invasivo } \\
\text { Carcinoma ductal invasivo, SOE } \\
\text { Carcinoma tipo misto } \\
\text { Carcinoma pleomórfico } \\
\text { Carcinoma com células gigantes tipo osteoclasto } \\
\text { Carcinoma com elementos coriocarcinomatosos } \\
\text { Carcinoma com elementos melanóticos }\end{array}$ \\
\hline Carcinoma lobular invasivo & $\begin{array}{l}\text { Carcinoma lobular invasivo } \\
\text { Carcinoma lobular clássico } \\
\text { Carcinoma lobular sólido } \\
\text { Carcinoma lobular alveolar } \\
\text { Carcinoma lobular pleomórfico } \\
\text { Carcinoma túbulo-lobular } \\
\text { Carcinoma lobular misto }\end{array}$ \\
\hline Carcinoma tubular & Carcinoma tubular \\
\hline Carcinoma cribriforme invasivo & Carcinoma cribriforme invasivo \\
\hline Carcinoma medular & $\begin{array}{l}\text { Carcinoma com elementos medulares } \\
\text { Carcinoma medular } \\
\text { Carcinoma medular atípico } \\
\text { Carcinoma invasivo SOE com elementos } \\
\text { medulares }\end{array}$ \\
\hline \multirow[t]{2}{*}{$\begin{array}{l}\text { Carcinoma mucinoso e outros tumores com abundante } \\
\text { mucina } \\
\text { Carcinoma mucinoso } \\
\text { Cistoadenocarcinoma e carcinoma mucinoso com células } \\
\text { colunares } \\
\text { Carcinoma de células em anel de sinete }\end{array}$} & Carcinoma mucinoso \\
\hline & $\begin{array}{l}\text { Carcinoma com diferenciação em células em anel } \\
\text { de sinete }\end{array}$ \\
\hline \multicolumn{2}{|l|}{$\begin{array}{l}\text { Tumores neuroendócrinos } \\
\text { Carcinoma neuroendócrino sólido } \\
\text { Tumor carcinoide atípico } \\
\text { Carcinoma de pequenas células/oat cell } \\
\text { Carcinoma neuroendócrino de grandes células }\end{array}$} \\
\hline \multicolumn{2}{|l|}{ Carcinoma papilar invasivo } \\
\hline Carcinoma micropapilar invasivo & Carcinoma micropapilar invasivo \\
\hline Carcinoma apócrino & Carcinoma com diferenciação apócrina \\
\hline
\end{tabular}


Tipos de tumores epiteliais segundo a $3^{\mathrm{a}}$ e $4^{\mathrm{a}}$ edições da Classificação Histológica de Tumores da

Tabela 1 Mama da OMS (cont.)

\section{$3^{\mathrm{a}}$ edição (2003)}

Carcinoma metaplásico

Carcinoma metaplásico epitelial puro

Carcinoma de células escamosas

Adenocarcinoma com metaplasia de células fusiformes

Carcinoma mucoepidermoide

Carcinomas metaplásicos mistos epiteliais/mesenquimais

\section{$4^{\mathrm{a}}$ edição (2012)}

Carcinoma metaplásico sem tipo especial

Carcinoma adenoescamoso de baixo grau Carcinoma metaplásico fibromatose-símile Carcinoma de células escamosas Carcinoma de células fusiformes Carcinoma metaplásico com diferenciação mesenquimal

Diferenciação condroide

Diferenciação óssea

Diferenciação em outros tipos mesenquimais Carcinoma metaplásico misto

Carcinoma mioepitelial

Carcinoma rico em lípides

Carcinoma secretor

Carcinoma oncocítico

Carcinoma adenoide cístico

Carcinoma de células acinares

Carcinoma de células claras rico em glicogênio

Carcinoma sebáceo

Carcinoma inflamatório

OMS: Organização Mundial da Saúde; SOE: sem outra especificação.

\section{Tabela 2 da OMS (2012)*}

\section{Tipos tumorais epiteliais raros segundo a $4^{\mathrm{a}}$ edição da Classificação Histológica de Tumores da Mama}

Tipos raros de carcinomas invasivos da mama

Carcinoma com elementos neuroendócrinos

Tumor neuroendócrino bem diferenciado

Carcinoma neuroendócrino pouco diferenciado (carcinoma de pequenas células)

Carcinoma com diferenciação neuroendócrina

Carcinoma secretor

Carcinoma papilar invasivo

Carcinoma de células acinares

Carcinoma mucoepidermoide

Carcinoma oncocítico

Carcinoma rico em lípides

Carcinoma de células claras rico em glicogênio

Carcinoma sebáceo

Tumores tipo glândula salivar/anexos cutâneos

Cilindroma

Hidroadenoma de células claras

* Na $3^{a}$ edição, esses tumores eram listados entre os carcinomas invasivos, sem chamar a atenção para sua raridade.

OMS: Organização Mundial da Saúde. 


\section{Carcinomas metaplásicos}

Devido à grande heterogeneidade e ao diferente perfil evolutivo deste grupo de neoplasias, o Comitê de Consenso propôs subclassificar os carcinomas metaplásicos de forma descritiva (Tabela 1). O subtipo fibromatose-símile ${ }^{(15)}$ foi reconhecido e ganhou nova codificação (ICD-O: 8572/3). A importância desse subtipo descrito em 1999 é o diagnóstico diferencial com lesões e tumores fusocelulares benignos, principalmente em biópsias por agulha com amostra limitada ou quando estes ocorrem associados a lesões esclerosantes/cicatrizes radiais ou papilomas ${ }^{(16)}$. Estudo imuno-histoquímico para citoqueratinas (CK), especialmente as de alto peso molecular (34ß E-12, CK-5 ou CK-5/6), e p63 auxilia no diagnóstico diferencial e cora positivamente as células fusiformes tumorais. Os diagnósticos diferenciais incluem lesões fusocelulares benignas (fibromatose, fasciite nodular, miofibroblastoma e nódulos reativos pós-biópsia por agulha) ${ }^{(17)}$ e sarcomas fusocelulares de baixo grau $^{(28,33)}$. Ampla amostragem das lesões é recomendada para o diagnóstico adequado. Estudos recentes empregando microarranjos de ácido desoxirribonucleico (DNA) demonstraram que os carcinomas metaplásicos são preferencialmente classificados como subtipo basal(55). Além disso, os carcinomas metaplásicos fusocelulares exibem marcadores de células-tronco tumorais e de transição epitélio-mesênquima e foram enquadrados no subtipo referido como claudin-low, descrito mais recentemente $\mathrm{e}^{(23,24,30)}$. O prognóstico dos carcinomas metaplásicos é ainda pouco conhecido e parece variar de acordo com os diferentes subtipos. Algumas séries mostram que eles têm pior resposta a quimioterapia adjuvante comparados a outros tumores triplonegativos ${ }^{(24,25,31)}$. No entanto, estudos independentes mostram que os subtipos fibromatose-símile e adenoescamoso exibem melhor prognóstico que outros subtipos, e mostram maior tendência a recidiva local do que a sistêmica da doença ${ }^{(15,45,46)}$.

\section{Carcinomas com características medulares}

Nesta $4^{a}$ edição, foram incluídos carcinoma medular (anteriormente referido como medular clássico ou típico, código ICD-O: 8510/3), carcinoma medular atípico e CDI-SOE com elementos ou características medulares (Tabela 1). Novos códigos foram atribuídos aos subtipos medular atípico (ICD-O: 8513/3) e CDI-SOE com elementos medulares (ICD-O: 8500/3). O diagnóstico do carcinoma medular clássico inclui arquitetura sincicial $>75 \%$ da massa tumoral, crescimento circunscrito com margens expansivas, ausência de diferenciação tubular, proeminente e difuso infiltrado inflamatório linfoplasmocitário peritumoral. Os termos carcinoma medular atípico e CDI-SOE com elementos medulares foram propostos para os tumores que não apresentam todas as características descritas nos carcinomas medulares clássicos. No entanto, devido à grande variação na reprodutibilidade diagnóstica entre os diferentes observadores, o Grupo de Consenso da $4^{a}$ edição sugeriu que os carcinomas medulares devem ser todos agrupados sob a denominação de carcinomas com elementos medulares. Estudos mais recentes mostram que os carcinomas medulares são, em sua maioria, triplonegativos (receptores hormonais e receptor do fator de crescimento epidérmico 2 [HER2] negativos) e de fenótipo basal(3). Eles expressam de forma variada CK de alto peso molecular (CK5, CK 5/6 e CK14), actina de músculo liso, receptor do fator de crescimento epidérmico 1 (EGFR), p53 e caveolina $^{(21,35)}$. Instabilidade genômica é uma alteração comum nos tumores medulares. A maioria dos tumores de pacientes com mutações germinativas do gene BRCA1 exibe elementos medulares $^{(3,53)}$. No entanto, apenas $13 \%$ dos pacientes com carcinoma medular exibem mutações germinativas no gene BRCAl(13). Alterações somáticas também foram observadas nos genes BRCA1 e TP53, além de hipermetilação do BRCA1, sugerindo um possível papel destes genes no desenvolvimento dos tumores medulares ${ }^{(36)}$. Embora os carcinomas medulares exibam alto grau histológico, eles são tradicionalmente considerados de melhor prognóstico, quando comparados com os CDI-SOE de alto grau. Admite-se que o bom prognóstico dos carcinomas medulares esteja relacionado com o infiltrado inflamatório linfoplasmocitário proeminente, rico em linfócitos T CD3+ e linfócitos T CD8+(42).

\section{Biomarcadores e classificação molecular dos tumores de mama}

Recentes avanços tecnológicos, incluindo novos anticorpos e metodologias imuno-histoquímicas, microdissecção a laser, uso de microarranjos de DNA e sequenciamento de última geração, têm permitido melhorar a compreensão das bases moleculares e celulares da iniciação e da progressão do câncer de mama. Essas metodologias permitiram refinar a taxonomia do câncer de mama e classificar os tumores da mama baseando-se em expressão proteica (proteômica) e de genes (genômica). Tecnologias de análise genômica e de expressão de microarranjos de DNA permitem examinar simultaneamente milhares de genes, subclassificar os tumores e estabelecer assinaturas genéticas preditivas de bom ou mau prognóstico ou de alta ou baixa possibilidade de resposta a tratamentos. 


\section{Marcadores preditivos em câncer de mama}

Os biomarcadores amplamente validados para prática clínica rotineira até o momento atual são os receptores hormonais (estrógeno e progesterona) e HER2. A avaliação rotineira desses três marcadores está indicada em todos os casos de câncer de mama por comitês de consenso oncológicos internacionais, como a Conferência de Saint Gallen $2011^{(19)}$. Atualmente, o método imuno-histoquímico usando amostras fixadas em formol e incluídas em parafina é o mais empregado e fornece informações prognósticas e preditivas. Recomendações de como realizar os testes e interpretá-los, bem como níveis de corte (cut-offs) adotados, foram propostos pelo Consenso do College of American Pathologists e American Society of Clinical Oncologists (CAP/ASCO)(22,56). O Comitê de Consenso da OMS considera altamente recomendável que os laboratórios que realizam imuno-histoquímica padronizem as fases pré-analítica, analítica e pós-analítica dos testes e participem de programas de controle de qualidade internos e externos. O cut-off recomendado para interpretação dos receptores hormonais é de $>1 \%$ de células tumorais com coloração nuclear positiva, de intensidade moderada a intensa. Para interpretação imuno-histoquímica do HER2 foi adotado o cut-off em $>30 \%$ de células tumorais invasivas com coloração membranosa forte (3+), marcando toda a circunferência da célula. Os tumores que exibem coloração moderada em $>30 \%$ das células ou forte em $<30 \%$ das células são referidos como indeterminados (2+) e devem ser reavaliados empregando o método de amplificação gênica (hibridação in situ por fluorescência [FISH], hibridação in situ colorimétrica [CISH] ou hibridação in situ prata [SISH]).

\section{Testes para classificação molecular, assinatura gênica e avaliação preditiva de recorrência do câncer de mama}

Muitos testes têm sido propostos para subestratificar os cânceres em grupos moleculares e identificar pacientes com câncer de mama de forma personalizada, identificando melhor os tumores de grau intermediário (de baixo ou alto risco) e os tumores com maior possibilidade de recorrência ${ }^{(40,48)}$. A definição do perfil de expressão gênica usando microarranjos de DNA ainda é dispendiosa e metodologicamente difícil para uso rotineiro em laboratórios de anatomia patológica. A identificação de subgrupos moleculares (luminais A e B, HER2 e basal) empregando imuno-histoquímica é possível, especialmente para os subtipos luminais e HER2. No entanto, não há consenso de quais marcadores devem ser utilizados e os cut-offs a serem empregados para identificar os tumores tipo basal ${ }^{(2,34,43,44)}$. Alguns testes já estão disponíveis comercialmente, como o teste preditor de subtipos tumorais de 50 genes (PAM50) ${ }^{(10,41)}$, para estratificação de tumores em bom ou mau prognóstico (teste de 70 genes) $)^{(51,52)}$ e para definir o alto ou o baixo risco de recorrência (escore de recorrência de 21 genes) $)^{(39)}$, entre outros. Esses testes são altamente promissores e já são indicados por oncologistas para seleção de pacientes para quimioterapia adjuvante. No entanto, o teste de 70 genes, o escore de recorrência de 21 genes e o PAM50 ainda estão em fase de validação em estudos clínicos randomizados com maior número de pacientes e seu uso rotineiro ainda não é recomendado por consensos internacionais ${ }^{(2,7,18,26)}$. Embora o Comitê de Consenso considere que os testes moleculares são altamente promissores, muito ainda precisa ser feito para melhorar a padronização da fase pré-analítica, as plataformas moleculares, o controle de qualidade, os métodos de análise estatística e os cut-offs usados para separar os cânceres em diferentes grupos moleculares.

\section{Lesões proliferativas intraductais}

O Comitê de Consenso da $4^{\mathrm{a}}$ edição optou pela adoção da terminologia clássica ou tradicional das lesões proliferativas intraductais. Esse grupo inclui um espectro heterogêneo de proliferações epiteliais, desde hiperplasias ductais usuais (ou sem atipias), até o carcinoma ductal in situ (Tabela 3). A classificação tradicional sofre com a variabilidade no diagnóstico interobservador, em especial na distinção entre hiperplasia ductal atípica e carcinoma ductal in situ de baixo grau. Tavassoli $(49,50)$ propôs a terminologia neoplasia intraepitelial ductal (NID) para as lesões proliferativas intraductais, reservando a expressão carcinoma para os tumores invasivos. No entanto, essa proposta não ganhou aceitação por não incorporar novos critérios diagnósticos e nem auxiliar a reduzir a discordância diagnóstica entre patologistas. Novas análises moleculares e genéticas das lesões proliferativas intraductais estão em estudo e espera-se que seu uso possa permitir meIhor identificação e classificação desse grupo de lesões. Dessa forma, o Comitê de Consenso considerou que o conceito e a terminologia das lesões proliferativas intraductais devem ser vistos como um processo em evolução, que poderá ser modificado quando novos dados moleculares e genéticos forem incorporados na classificação dessas lesões. 


\section{Lesões proliferativas intraductais e lesões precursoras segundo a $3^{\mathrm{a}}$ e $4^{\mathrm{a}}$ edições da Classificação}

Tabela 3 Histológica de Tumores da Mama da OMS

\begin{tabular}{|c|c|}
\hline $3^{\mathrm{a}}$ edição (2003) & $4^{\mathrm{a}}$ edição (2012) \\
\hline & Lesões precursoras \\
\hline $\begin{array}{l}\text { Neoplasia lobular } \\
\text { Carcinoma ductal in situ }\end{array}$ & $\begin{array}{l}\text { Carcinoma ductal in situ } \\
\text { Neoplasia lobular } \\
\text { Carcinoma lobular in situ } \\
\text { Carcinoma lobular in situ clássico } \\
\text { Carcinoma lobular in situ pleomórfico } \\
\text { Hiperplasia lobular atípica }\end{array}$ \\
\hline Lesões proliferativas intraductais & Lesões proliferativas intraductais \\
\hline Hiperplasia ductal usual & Hiperplasia ductal usual \\
\hline Atipia epitelial plana & $\begin{array}{l}\text { Lesões de células colunares } \\
\text { Atipia epitelial plana }\end{array}$ \\
\hline Hiperplasia ductal atípica & Hiperplasia ductal atípica \\
\hline Carcinoma ductal in situ & Carcinoma ductal in situ \\
\hline
\end{tabular}

OMS: Organização Mundial da Saúde.

\section{Lesões de células colunares e atipia epitelial plana}

Houve mudança importante na classificação dessas lesões na $4^{a}$ edição, sendo a mais importante a divisão em dois grupos: lesões de células colunares e atipias epiteliais planas (Tabela 3).

\section{Lesões de células colunares}

As lesões referidas como lesões ou alterações de células colunares (LCC) englobam a alteração de células colunares e hiperplasia de células colunares sem atipias. As LCC afetam as unidades ductulobulares terminais, que ficam aumentadas, com ácinos dilatados, revestidos por células colunares altas, com frequente secreção apical (apical snouts); secreção luminal e microcalcificações são frequentes. As células que revestem as LCC têm núcleos ovoides, dispostos perpendicularmente à membrana basal, com a cromatina fina, dispersa uniformemente e sem atipias significativas. Lesões com uma a duas camadas de células revestindo os espaços são referidas como alteração de células colunares; lesões com mais de duas camadas de células ou formação de tufos celulares são denominadas hiperplasia de células colunares.

Outros termos aplicados anteriormente às LCC foram: adenose de ductos rombos ou blunt duct adenosis, alteração colunar dos lóbulos com decapitação de secreção, metaplasia colunar, unidades lobulares alargadas, unidades lobulares aumentadas com alteração colunar, entre ou$\operatorname{tros}^{(47)}$. As LCC frequentemente estão associadas a cistos e lesões proliferativas epiteliais. É frequente a associação das LCC com neoplasia lobular (hiperplasia lobular atípica e carcinoma lobular in situ) ${ }^{(8,20)}$. As LCC exibem positividade forte para receptores hormonais ${ }^{(32)}$ e são negativas para HER2.

Estudos recentes com seguimento clínico de pacientes com LCC mostram que essas lesões estão associadas a risco muito baixo para o desenvolvimento subsequente de carcinoma invasor (risco relativo de cerca de 1,5x). Ademais, o risco associado a essas lesões não é claramente independente do risco associado a outras lesões proliferativas concomitantes ${ }^{(1,5,6)}$.

\section{Atipia epitelial plana}

O termo atipia epitelial plana (AEP) ou flat epithelial atypia, conforme definido nesta $4^{a}$ edição, fica restrito apenas às alterações neoplásicas das unidades ductulobulares terminais, que são dilatadas e revestidas por uma ou mais camadas de células monomórficas, com baixo grau de atipia e perda da polaridade. Os núcleos são redondos, uniformes e com nucléolos pequenos ou pouco evidentes, semelhantes às células dos carcinomas ductais in situ de baixo grau. As células podem ser cuboidais ou colunares, com frequente decapitação apical de secreção. Secreção 
luminal e microcalcificações são frequentes. Há também forte associação entre atipia plana e a coexistência de neoplasia lobular (hiperplasia lobular atípica [HLA] e carcinoma lobular in situ [CLIS]), hiperplasia ductal atípica, carcinoma ductal in situ de baixo grau e carcinomas invasores de baixo grau, incluindo carcinoma tubular ${ }^{(8,29)}$. Azzopardi propôs o termo clinging carcinoma tipo monomórfico para as lesões agora denominadas de atipia epitelial plana ${ }^{(27)}$. O Comitê de Consenso da $4^{a}$ edição recomenda que apenas as lesões proliferativas planas com alto grau nuclear sejam referidas como carcinoma ductal in situ.

Do ponto de vista prognóstico, a AEP tem mais interesse científico como lesão inicial na via evolutiva das neoplasias de baixo grau do que lesão com importância clínica como precursora ou marcadora de risco. Poucos dados disponíveis, oriundos de séries pequenas, com seguimento clínico muito limitado, sugerem que alguns casos de AEP possam evoluir para carcinoma invasor ${ }^{(4,14)}$. Esses dados sugerem que o risco evolutivo para câncer de mama associado a essas lesões parece ser bem inferior ao risco associado às hiperplasias ductais e lobulares atípicas. Portanto, apesar da presença de atipia no nome, a AEP não deve ser considerada equivalente a hiperplasia ductal ou lobular atípica do ponto de vista de manejo clínico do paciente. Resultados de pequenas séries de estudos retrospectivos mostram que até $30 \%$ dos pacientes com AEP em biópsia por agulha têm lesão mais avançada na biópsia excisional. Entretanto, devido às limitações dos estudos e à grande variação nos tempos de seguimento após a biópsia inicial, ainda é incerto se há necessidade de se indicar excisão cirúrgica após diagnóstico de AEP em biópsia por agulha. Correlação radiológica e patológica é recomendada para determinação da conduta subsequente.

\section{Neoplasia lobular}

A expressão neoplasia lobular refere-se a todo espectro de lesões epiteliais atípicas que envolvem a unidade ductolobular terminal, caracterizadas pela proliferação de células pequenas, uniformes, redondas, sem coesão celular e com ou sem extensão pagetoide para ductos terminais. Nesta $4^{a}$ edição, fez-se a distinção entre HLA e CLIS baseando-se na extensão do envolvimento das unidades lobulares ${ }^{(37,38)}$. CLIS clássico é diagnosticado quando mais da metade dos ácinos de um lóbulo estão expandidos e distorcidos pelas células proliferadas; a extensão pagetoide aos ductos terminais é comum. A HLA envolve menos de $50 \%$ dos ácinos. As lesões são multicêntricas em até $85 \%$ das pacientes e bilaterais em
30\%-67\%. As células do CLIS clássico podem apresentar atipia nuclear leve a moderada (anteriormente referidas como tipos A e B). Mais recentemente, outras variantes de CLIS foram reconhecidas devido à associação com microcalcificações detectadas à mamografia e referidas como variantes pleomórficas. Estas incluem: (1) lesões com características de CLIS clássico, com perda de coesão celular e com áreas de necrose tipo comedo; e (2) lesões com pleomorfismo nuclear acentudo, semelhante ao CDIS de alto grau, com ou sem características apócrinas (CLIS pleomórfico apócrino). O CLIS pleomórfico ganhou codificação própria nesta $4^{\text {a }}$ edição (ICD-O: 8519/2), diferente do aplicado ao CLIS clássico (ICD-O: 8520/2). Essas lesões perdem tipicamente a expressão de E-caderina e mostram alterações genômicas típicas das neoplasias lobulares invasoras (perdas em 16q e ganhos em 1q ${ }^{(9)}$. A perda de expressão imuno-histoquímica de E-caderina pode ser útil na diferenciação entre carcinoma ductal in situ e CLIS pleomórfico. Entretanto, o diagnóstico não deve ser baseado apenas no imunofenótipo e na perda de expressão da E-caderina, mas na análise criteriosa das imunocolorações aliada à avaliação da distribuição topográfica das lesões. Casos de neoplasia lobular podem ser positivos para E-caderina devido a mutações e expressão aberrante da proteína ${ }^{(11)}$. Do ponto de vista prognóstico, ainda não há estudos que comprovem evolução clínica diferente para essas lesões em relação ao CLIS clássico. O significado clínico do tipo pleomórfico e se os pacientes necessitam de tratamentos diferentes ainda não estão bem definidos. Análises moleculares de neoplasias lobulares sincrônicas com carcinoma lobular invasor, tanto do tipo clássico quanto da variante pleomórfica, demonstram concordância no perfil genômico e indicam que os CLIS são lesões precursoras, porém, não obrigatórias, dos carcinomas lobulares invasores ${ }^{(12,54)}$.

\section{Mudanças na classificação de outras lesões e tumores da mama}

Houve ainda mudanças na forma de classificar os tumores epiteliais/mioepiteliais (Tabela 4), as lesões e as neoplasias papilares (Tabela 5), as proliferações epiteliais benignas (Tabela 6) e os tumores mesenquimais (Tabela 7). Para maiores detalhes sobre mudanças nos descritores e novos marcadores moleculares, utilizados principalmente no estudo imuno-histoquímico, o leitor deverá reportar-se diretamente ao fascículo. 


\section{Tabela 4 Mama da OMS}

Tumores epiteliais/mioepiteliais segundo a $3^{\mathrm{a}}$ e $4^{\mathrm{a}}$ edições da Classificação Histológica de Tumores da

\begin{tabular}{|c|c|}
\hline $3^{\text {a }}$ edição (2003) & $4^{\mathrm{a}}$ edição (2012) \\
\hline Lesões mioepiteliais & Tumores epiteliais/mioepiteliais \\
\hline Mioepiteliose & Adenoma pleomórfico \\
\hline Adenose adenomioepitelial & $\begin{array}{l}\text { Adenomioepitelioma } \\
\text { Adenomioepitelioma com carcinoma }\end{array}$ \\
\hline Adenomioepitelioma & Carcinoma adenoide cístico \\
\hline Mioepitelioma maligno & \\
\hline
\end{tabular}

OMS: Organização Mundial da Saúde.

\section{Tabela 5 Mama da OMS*}

\section{$3^{\mathrm{a}}$ edição (2003)}

Neoplasias papilares intraductais

Papiloma central

Papiloma periférico

Papiloma atípico

Carcinoma papilífero intraductal

Carcinoma papilífero intracístico

\section{$4^{\mathrm{a}}$ edição (2012)}

\section{Lesões papilares}

Papiloma intraductal

Papiloma intraductal com hiperplasia atípica

Papiloma intraductal com carcinoma ductal in situ

Papiloma intraductal com carcinoma lobular in situ

Carcinoma papilífero intraductal

Carcinoma papilífero encapsulado

Carcinoma papilífero encapsulado com invasão

Carcinoma papilífero sólido

In situ

Invasivo

* Na $3^{a}$ edição, o carcinoma papilifero invasivo foi incluído entre os carcinomas invasivos e, na $4^{a}$ edição, entre os tipos raros de tumores da mama. OMS: Organização Mundial da Saúde.

\section{Proliferações epiteliais benignas segundo a $3^{\mathrm{a}}$ e $4^{\mathrm{a}}$ edições da Classificação Histológica de Tumores}

Tabela 6 da Mama da OMS

\section{$3^{\mathrm{a}}$ edição (2003)}

Adenoses incluindo variantes

Adenose esclerosante

Adenose apócrina

Adenose microglandular

Adenose de ductos rombos (blunt duct adenosis)

Adenose adenomioepitelial

Cicatriz radial/lesão esclerosante complexa

Adenomas

Adenoma tubular

Adenoma lactante

Adenoma apócrino

Adenoma pleomórfico

Adenoma ductal

\section{$4^{\mathrm{a}}$ edição (2012)}

Adenose esclerosante

Adenose apócrina

Adenose microglandular

Cicatriz radial/lesão esclerosante complexa

Adenomas

Adenoma tubular

Adenoma lactante

Adenoma apócrino

Adenoma ductal

OMS: Organização Mundial da Saúde. 
Tabela 7

\section{Tumores mesenquimais segundo a $3^{\mathrm{a}}$ e $4^{\mathrm{a}}$ edições da Classificação Histológica de Tumores da Mama}

\begin{tabular}{|c|c|}
\hline $3^{\mathrm{a}}$ edição (2003) & $4^{\mathrm{a}}$ edição (2012) \\
\hline $\begin{array}{l}\text { Hemangioma } \\
\text { Angiomatose } \\
\text { Hemangiopericitoma } \\
\text { Hiperplasia pseudoangiomatosa do estroma } \\
\text { Miofibroblastoma } \\
\text { Fibromatose (agressiva) } \\
\text { Tumor miofibroblástico inflamatório } \\
\text { Lipoma } \\
\text { Angiolipoma } \\
\text { Tumor de células granulares } \\
\text { Neurofibroma } \\
\text { Schwanoma } \\
\text { Angiossarcoma } \\
\text { Lipossarcoma } \\
\text { Rabdomiossarcoma } \\
\text { Osteossarcoma } \\
\text { Leiomioma } \\
\text { Leiomiossarcoma }\end{array}$ & $\begin{array}{l}\text { Fasciite nodular } \\
\text { Miofibroblastoma } \\
\text { Fibromatose tipo desmoide } \\
\text { Tumor miofibroblástico inflamatório } \\
\text { Lesões vasculares benignas } \\
\text { Hemangioma } \\
\text { Angiomatose } \\
\text { Lesões vasculares atípicas } \\
\text { Hiperplasia pseudoangiomatosa do estroma } \\
\text { Tumor de células granulares } \\
\text { Tumores benignos da bainha de nervo periférico } \\
\text { Neurofibroma } \\
\text { Schwanoma } \\
\text { Lipoma } \\
\text { Angiolipoma } \\
\text { Lipossarcoma } \\
\text { Angiossarcoma } \\
\text { Rabdomiossarcoma } \\
\text { Osteossarcoma } \\
\text { Leiomioma } \\
\text { Leiomiossarcoma }\end{array}$ \\
\hline
\end{tabular}

OMS: Organização Mundial da Saúde.

\section{Considerações finais}

Fica evidente nesta breve atualização que houve avanços significativos na compreensão dos aspectos patogenéticos e evolutivos de muitas lesões e tumores da mama nessa última década. As mudanças foram incorporadas na $4^{\text {a }}$ edição dos tumores da OMS, baseando-se principalmente em novos conhecimentos moleculares e genéticos dos tumores. No entanto, avanços contínuos ocorrerão com mudanças futuras de alguns conceitos e terminologias, que irão melhorar os diagnósticos e os tratamentos, beneficiando os pacientes.

Em resumo, nesta atualização, destacaram-se como principais modificações apresentadas na $4^{\mathrm{a}}$ edição da Classificação dos Tumores de Mama da OMS:

- o fascículo atual é dedicado integralmente aos tumores da mama;

- os tumores epiteliais foram agrupados de forma diferente, com o reconhecimento de nove tipos especiais e suas variantes e 11 tipos raros de tumores mamários, além do carcinoma ductal invasivo sem outra especificação. Foram reconhecidos e incluídos novos códigos para as variantes de carcinoma lobular, carcinomas com características medulares e dos subtipos de carcinomas metaplásicos;

- foram sugeridos novos escores para avaliação imuno-histoquímica de receptores hormonais ( $>1 \%$ de células positivas) e HER2 (> 30\% células positivas);

- apresentou-se nova abordagem da classificação molecular e genômica do câncer de mama, incluindo novos testes que empregam perfil de expressão gênica para predição da evolução clínica e resposta terapêutica;

- foi mantida a terminologia tradicional das lesões proliferativas intraductais, não se recomendando a terminologia de neoplasia intraepitelial ductal;

- reconheceu-se a importância prognóstica de se distinguir hiperplasia lobular atípica e CLIS dentro do espectro das neoplasias lobulares;

- as lesões de células colunares (alteração e hiperplasia de células colunares sem atipias) foram separadas das atipias epiteliais planas, cuja evolução biológica ainda é pouco definida. 


\section{Referências}

1. ARONER, S. A. et al. Columnar cell lesions and subsequent breast cancer risk: a nested case-control study. Breast Cancer Res, v. 12, n. 4, p. R61, 2010.

2. BADVE, S. et al. Basal-like and triple-negative breast cancers: a critical review with an emphasis on the implications for pathologists and oncologists. Mod Pathol, v. 24, n. 2, p. 157-67, 2011.

3. BERTUCCI, F. et al. Gene expression profiling shows medullary breast cancer is a subgroup of basal breast cancers. Cancer Res, v. 66, n. 9, p. 4636-44, 2006.

4. BIJKER, N. et al. Risk factors for recurrence and metastasis after breast-conserving therapy for ductal carcinoma in situ: analysis of European Organization for Research and Treatment of Cancer Trial 10853. J Clin Oncol, v. 19, n. 8, p. 2263-71, 2001.

5. BOULOS, F. I. et al. Clinicopathologic characteristics of carcinomas that develop after a biopsy containing columnar cell lesions: evidence against a precursor role. Cancer, v. 118, n. 9, p. 2372-7, 2012.

6. BOULOS, F. I. et al. Histologic associations and long-term cancer risk in columnar cell lesions of the breast: a retrospective cohort and a nested case-control study. Cancer, v. 113, n. 9, p. 2415-21, 2008.

7. BUENO-DE-MESQUITA, J. M. et al. Validation of 70-gene prognosis signature in node-negative breast cancer. Breast Cancer Res Treat, v. 117, n. 3, p. 483-95, 2009.

8. CARLEY, A. M. et al. Frequency and clinical significance of simultaneous association of lobular neoplasia and columnar cell alterations in breast tissue specimens. Am J Clin Pathol, v. 130, n. 2, p. 254-8, 2008.

9. CHEN, Y. Y. et al. Genetic and phenotypic characteristics of pleomorphic lobular carcinoma in situ of the breast. Am J Surg Pathol, v. 33, n. 11, p. 1683-94, 2009.

10. CHIA, S. K. et al. A 50-gene intrinsic subtype classifier for prognosis and prediction of benefit from adjuvant tamoxifen. Clin Cancer Res, v. 18, n. 16, p. 4465-72, 2012.

11. DA SILVA, L. et al. Aberrant expression of E-cadherin in lobular carcinomas of the breast. Am J Surg Pathol, v. 32, n. 5, p. 773-83, 2008.

12. DE LEEUW, W. J.; CORNELISSE, C. J.; CLETON-JANSEN, A. M. Simultaneous loss of E-cadherin and catenins in invasive lobular breast cancer and lobular carcinoma in situ. J Pathol, v. 183, n. 4, p. 404-11, 1997.

13. EISINGER, F. et al. BRCA1 and medullary breast cancer. JAMA, v. 280, n. 14, p. 1227-8, 1998.

14. EUSEBI, V. et al. Rilke F. Long-term follow-up of in situ carcinoma of the breast. Semin Diagn Pathol, v. 11, n. 3, p. 223-35, 1994.

15. GOBBI, H. et al. Metaplastic breast tumors with a dominant fibromatosis-like phenotype have a high risk of local recurrence. Cancer, v. 85, n. 10, p. 2170-82, 1999.

16. GOBBI, H. et al. Reactive spindle cell nodules of the breast after core biopsy or fine-needle aspiration. Am J Clin Pathol, v. 113, n. 2, p. 288-94, 2000.

17. GOBBI, H. et al. Metaplastic spindle cell breast tumors arising within papillomas, complex sclerosing lesions, and nipple adenomas. Mod Pathol, v. 16, n. 9, p. 893901, 2003.
18. GÖKMEN-POLAR, Y.; BADVE, S. Molecular profiling assays in breast cancer: are we ready for prime time? Oncology (Williston Park), v. 26, n. 4, p. 350-7, 2012.

19. GOLDHIRSCH, A. et al. Strategies for subtypes--dealing with the diversity of breast cancer: highlights of the St. Gallen international expert consensus on the primary therapy of early breast cancer 2011. Ann Oncol, v. 22, n. 8, p. 1736-47, 2011.

20. GOMES, D. S. et al. Lobular neoplasia: frequency and association with other breast lesions. Diagn Pathol, v. 6 , p. 74, 2011.

21. GUO, X. et al. Tumor infiltrating lymphocytes differ in invasive micropapillary carcinoma and medullary carcinoma of breast. Mod Pathol, v. 21, n. 9, p. 1101-7, 2008.

22. HAMMOND, M. E. et al. American Society of Clinical Oncology/College of American Pathologists guideline recommendations for immunohistochemical testing of estrogen and progesterone receptors in breast cancer (unabridged version). Arch Pathol Lab Med, v. 134, n. 7, p. e48-72, 2010.

23. HENNESSY, B. T. et al. Characterization of a naturally occurring breast cancer subset enriched in epithelial-tomesenchymal transition and stem cell characteristics. Cancer Res, v. 69, n. 10, p. 4116-24, 2009.

24. HENNESSY, B. T. et al. Biphasic metaplastic sarcomatoid carcinoma of the breast. Ann Oncol, v. 17, n. 4, p. 605-13, 2006.

25. JUNG, S. Y. et al. Worse prognosis of metaplastic breast cancer patients than other patients with triple-negative breast cancer. Breast Cancer Res Treat, v. 120, n. 3, p. 627-37, 2010.

26. KELLY, C. M. et al. Agreement in risk prediction between the 21-gene recurrence score assay (Oncotype DX ${ }^{\circledR}$ ) and the PAM50 breast cancer intrinsic ClassifierT in early-stage estrogen receptor-positive breast cancer. Oncologist, v. 17, n. 4, p. 492-8, 2012.

27. LAKHANI S, R.; ELLIS, I. O.; SCHNITT, S. J.; TAN, P. H.; VAN DE VIJVER, M. J. (Eds.). WHO Classification of Tumours of the breast. Lyon: IARC, 2012.

28. LEE, A. H. et al. Recent developments in the histological diagnosis of spindle cell carcinoma, fibromatosis and phyllodes tumour of the breast. Histopathology, v. 52, n. 1, p. 45-57, 2008.

29. LEIBL, S.; REGITNIG, P.; MOINFAR, F. Flat epithelial atypia (DIN 1a, atypical columnar change): an underdiagnosed entity very frequently coexisting with lobular neoplasia. Histopathology, v. 50, n. 7, p. 85965, 2007.

30. LIEN, H. C. et al. Molecular signatures of metaplastic carcinoma of the breast by large-scale transcriptional profiling: identification of genes potentially related to epithelial-mesenchymal transition. Oncogene, v. 26, n. 57, p. 7859-71, 2007.

31. LUINI, A. Metaplastic carcinoma of the breast, an unusual disease with worse prognosis: the experience of the European Institute of Oncology and review of the literature. Breast Cancer Res Treat, v. 101, n. 3, p. 349-53, 2007. 
32. MCLAREN, B. K. et al. Immunohistochemical expression of estrogen receptor in enlarged lobular units with columnar alteration in benign breast biopsies: a nested case-control study. Am J Surg Pathol, v. 29, n. 1, p. 105-8, 2005.

33. CMENAMIN, M. E.; DESCHRYVER, K.; FLETCHER, C. D. Fibrous Lesions of the Breast: a review. Int J Surg Pathol, v. 8, n. 2, p. 99-108, 2000.

34. NIELSEN, T. O. et al. Immunohistochemical and clinical characterization of the basal-like subtype of invasive breast carcinoma. Clin Cancer Res, v. 10, n. 16, p. 5367-74, 2004.

35. ORLANDO, L. et al. Are all high-grade breast cancers with no steroid receptor hormone expression alike? The special case of the medullary phenotype. Ann Oncol, v. 16, n. 7, p. 1094-9, 2005.

36. OSIN, P. et al. Distinct genetic and epigenetic changes in medullary breast cancer. Int J Surg Pathol, v. 11, n. 3, p. 153-8, 2003.

37. PAGE, D. L. et al. Atypical lobular hyperplasia as a unilateral predictor of breast cancer risk: a retrospective cohort study. Lancet, v. 361, n. 9352, p. 125-9, 2003.

38. PAGE D. L. et al. Lobular neoplasia of the breast: higher risk for subsequent invasive cancer predicted by more extensive disease. Hum Pathol, v. 22, n. 12, p. 12329, 1991.

39. PAIK, S. et al. A multigene assay to predict recurrence of tamoxifen-treated, node-negative breast cancer. N Engl J Med, v. 351, n. 27, p. 2817-26, 2004.

40. PEROU, C. M. et al. Molecular portraits of human breast tumours. Nature, v. 406, n. 6797, p. 747-52, 2000.

41. PRAT, A. et al. PAM50 assay and the three-gene model for dentifying the major and clinically relevant molecular subtypes of breast cancer. Breast Cancer Res Treat, v. 135, n. 1, p. 301-6, 2012.

42. RAKHA, E. A. et al. The prognostic significance of inflammation and medullary histological type in invasive carcinoma of the breast. Eur J Cancer, v. 45, n. 10, p. 1780-7, 2009.

43. RAKHA, E. A. et al. Triple-negative breast cancer: distinguishing between basal and nonbasal subtypes. Clin Cancer Res, v. 15, n. 7, p. 2302-10, 2009.

44. RAKHA, E. A.; ELLIS, I. O. Triple-negative/basal-like breast cancer: review. Pathology, v. 41, n. 1, p. 40-7, 2009.
45. ROSEN, P. P.; ERNSBERGER, D. Low-grade adenosquamous carcinoma. A variant of metaplastic mammary carcinoma. Am J Surg Pathol, v. 11, n. 5, p. 351-8, 1987.

46. SILINI, E.; DIONIGI, P. Low-grade fibromatosis-like spindle cell metaplastic carcinoma: a basal-like tumor with a favorable clinical outcome. Report of two cases. Tumori, v. 95, n. 2, p. 264-7, 2009.

47. SCHNITT, S. J.; VINCENT-SALOMON, A. Columnar cell lesions of the breast. Adv Anat Pathol, v. 10, n. 3, p. 113-24, 2003.

48. SOTIRIOU, C. et al. Gene expression profiling in breast cancer: understanding the molecular basis of histologic grade to improve prognosis. J Natl Cancer Inst, v. 98, n. 4, p. 262-72, 2006.

49. TAVASSOLI, F. A. Breast pathology: rationale for adopting the ductal intraepithelial neoplasia (DIN) classification. Nat Clin Pract Oncol, v. 2, n. 3, p. 116-7, 2005.

50. TAVASSOLI, F. A.; DEVILLEE, P. (Eds.). World Health Organization classification of tumours. Pathology and genetics of tumours of the breast and female genital organs. Lyon: IARC, 2003.

51. VAN DE VIJVER, M. J. et al. A gene-expression signature as a predictor of survival in breast cancer. N Engl J Med, v. 347, n. 25, p. 1999-2009, 2002.

52. VAN'T VEER, L. J. et al. Expression profiling predicts outcome in breast cancer. Breast Cancer Res, v. 5, n. 1, p. 57-8, 2003.

53. VARGAS, A. C.; DA SILVA, L.; LAKHANI, S. R. The contribution of breast cancer pathology to statistical models to predict mutation risk in BRCA carriers. Fam Cancer, v. 9, n. 4, p. 545-53, 2010.

54. VOS, C. B. et al. E-cadherin inactivation in lobular carcinoma in situ of the breast: an early event in tumorigenesis. Br J Cancer, v. 6, n. 9, p. 1131-3, 1997.

55. WEIGELT, B.; KREIKE, B.; REIS-FILHO, J. S. Metaplastic breast carcinomas are basal-like breast cancers: a genomic profiling analysis. Breast Cancer Res Treat, v. 117, n. 2, p. 273-80, 2009.

56. WOLFF, A. C. et al. American Society of Clinical Oncology/ College of American Pathologists. American Society of Clinical Oncology/College of American Pathologists guideline recommendations for human epidermal growth factor receptor 2 testing in breast cancer. Arch Pathol Lab Med, v. 131, n. 1, p. 18-43, 2007. 